\title{
Emigration, wage differentials and brain drain: The case of Suriname
}

\author{
By \\ Tina Dulam \\ Anton de Kom University of Suriname \\ and \\ Philip Hans Franses \\ Erasmus School of Economics
}

Econometric Institute Report 2011-33

\begin{abstract}
In this paper we examine two hypotheses concerning emigration. The first hypothesis is that emigration is positively correlated with wage differentials. The second hypothesis concerns a positive correlation between emigration and higher education in the sending country (the socalled brain gain hypothesis). We analyze unique time series data for Suriname for 19722009, for which we fit error correction models to disentangle short-run from long-run effects. We document moderate support for the first hypothesis, but we find strong support for the brain drain (and not brain gain) hypothesis. We conclude with implications of our findings for Suriname.
\end{abstract}

Key words: Migration; Education; Brain drain

JEL code: F22; I25

This version: 24 October 2011

Address for correspondence: Tina Dulam, Faculty of Social Sciences, Anton de Kom University of Suriname, Leysweg 86, Paramaribo, Suriname, twdulam@gmail.com, tina.dulam@uvs.edu 


\section{Introduction}

The consequences of migration from developing countries to developed countries have been subject of research in many studies. In particular there is an interest in examining the effects on the formation of human capital in the sending countries. An established and frequently documented consequence is summarized in the brain drain theory. This theory predicts that emigration of highly skilled individuals from developing to developed countries would reduce the ability of the home country to build up human capital and hence would reduce its welfare. Recently, new insights have challenged this theory, and theoretical and empirical evidence has been presented for the so-called brain gain theory, see Fan and Stark (2007a, 2007b), Boucher et al. (2005) and Beine et al. (2001, 2007). In short, the main argument is that prospective migration opportunities stimulate education levels in the sending country since higher skilled individuals can earn higher wages in developed countries than in sending countries. This in turn could have a positive effect on the welfare of the sending country.

In the present paper we put these theories to an empirical test, using time series data for the South American country of Suriname. The case of Suriname is particularly useful as the receiving country (usually) concerns the Netherlands (for historical and language reasons) so that we can collect annual time series data for a reasonably long stretch of time.

The outline of our paper is as follows. In Section 2 we give a concise discussion of the relevant literature, and we formulate two testable hypotheses. In Section 3 we discuss the data collection and the construction of the relevant time series variables. In Section 4 we review our methodology, which amounts to the calibration of so-called error correction models. These models are useful as they allow discerning short-run and long-run effects. In Section 5 we present our empirical results. Our main conclusions are that emigration from Suriname is positively correlated with wage differentials and that we obtain strong support for the brain drain hypothesis. In Section 6 we discuss issues for further research and also the implications for Suriname.

\section{Background}

The literature on brain drain effects and, more recently, on possible brain gain effects is very large. With the advent of more and better data, recent studies can rely on large samples and 
detailed information, and this had led to a renewed interest to testing the hypotheses on brain drain or brain gain.

Beine et al. (2001) examined the brain gain hypothesis using cross-sectional data for 37 developing countries, and they find some support for this hypothesis. These authors suggest that it would be best to compile and analyze panel data, that is, data with a cross section and a time series dimension. Most important is time series data for human capital levels as that would be a key variable to be explained. Boucher et al. (2005) used longitudinal data covering the period 1980 to 2002 to examine the brain gain hypothesis for Mexico, which thus amounts to a cross section of size 1 . These authors use the average years of schooling of adults as a proxy for human capital (ibid, p. 8). In our study we also consider a single country, although we rely on various measures for human capital.

Batista et al. (2009) tested the brain gain hypothesis using household survey data for Cape Verde. These authors can rely on full histories of migrants. Although Batista et al. (2009), like us, examined a small developing country, they cannot draw firm conclusions as the time series dimension of the data is missing. In our empirical study below, we can examine the brain gain hypothesis in a dynamic setting for the small developing country of Suriname and we use multiple measures for human capital formation.

According to Eggert et al. (2009) and Beine et al. (2001), skilled people are better off in developed countries than in developing countries, as developed countries pay higher wages. The prospect of emigrating and acquiring higher wages abroad when being high skilled can stimulate people to achieve higher education levels. Hence, higher wage differentials between the home country (sending country) and the destination country should increase the emigration rate. Our first introductory hypothesis is thus that the wage differential between the sending and receiving countries is positively linked with the emigration rate.

Stark et. al. (1998), Boucher et al. (2005) and Beine et al. (2001, 2007) amongst others put forward the brain gain hypothesis. In short, the main argument is that prospective migration opportunities stimulate education levels in the sending country as higher skilled individuals can earn higher wages in developed countries than in sending countries. This in turn could have a positive effect on the welfare of the sending country. So, our second hypothesis is that the emigration rate of highly skilled people increases the education level of the home country. In other words, the level of human capital of the sending country is positively correlated with the emigration rate. 


\section{Data}

For many years Suriname has experienced high rates of emigration, especially to the Netherlands. With an emigration rate of $56.3 \%$ in 2000 , Suriname is one of the top 10 countries in the world with the highest emigration rate (International Organization for Migration 2010, p. 156). The number of immigrants from Suriname to the Netherlands in percentage of the Surinamese population was 38.8\% in 2000 (UN DESA 2009). The Surinamese amount to the largest group of immigrants living in the Netherlands.

According to Docquier (2006), the European Union has been the "main source of human capital flight from Suriname”. Nurse (2006) states that "The brain drain from the Caribbean is the highest in the world, with migration rates among the tertiary educated in excess of 60\% in Trinidad and Tobago, Jamaica, Guyana and Suriname”.

The small developing country of Suriname is situated along the Atlantic Ocean on the mainland of South America. Suriname has been a colony of the Netherlands for many years and it gained its independence in 1975. Its current population size (measured in 2004) is 492,829 and the surface area is $163,820 \mathrm{~km}^{2}$. Economic growth has been negative for most of the years after the independence from the Netherlands in 1975, but since 2003 the country is experiencing positive economic growth per capita with an estimated growth of $4.5 \%$ in 2010 (IMF, 2011) . Although economic growth is on the rise, poverty and inequality levels are high. Soedhwa (2005) estimated the percentage of Surinamese living below the national poverty line to be $65 \%$ in 2001 . The income share held by the richest $20 \%$ in 1999 was $57 \%$, while the poorest 20\% had an income share of 3\% (World Bank, 2011).

Data on the emigration rate by educational level are not available. Therefore we use the gross emigration rate, that is, the yearly number of emigrants from Suriname to the Netherlands as a share of the population of Suriname as a proxy for the emigration rate (we use the acronym "mig_emig”). Another proxy for the emigration rate that could be used is the difference between the yearly number of first generation immigrants (Dutch: allochtonen) in the Netherlands from Suriname as a share of the population of Suriname in year $t$ and year $t-1$. The first proxy for the emigrate rate is calculated using data from the General Bureau of Statistics of Suriname and the latter from the Central Bureau of Statistics of the Netherlands. When analyzing the overlap between the two variables we see that the correlation is close to 1. Hence, we consider only the mig_emig variable.

Yearly data on the completion rate at the primary and secondary level for the full period 1972 until 2009 were not available. However, yearly data on the number of graduated 
students at the Anton de Kom University of Suriname were acquired from the library of the university. Yearly data on the number of enrolled pupils and students at primary, secondary and tertiary levels were acquired from the General Bureau of Statistics of Suriname. Unfortunately, for some years the data are missing. We use the following proxies for the educational levels. First, we have the yearly gross school enrolment rate at primary level (\% gross), that is, the number of enrolled pupils at primary schools as a share of the school age population of that primary level (variable name: schlenrlpr). The data were obtained from the UNESCO UIS database. Next, the yearly gross school enrolment rate at the secondary level (\% gross) is the number of enrolled students at secondary schools as a share of the school age population at that secondary level (variable name: schlenrlsc). Again, the data were obtained from the UNESCO UIS database. Further, the yearly gross school enrolment rate at the tertiary level is the number of enrolled students at the university in percentage of the school age population at that tertiary level. These numbers were obtained from the Anton de Kom University of Suriname and from the General Bureau for the Statistics in Suriname (variable name: schlenrltr). Note that there is only one university in Suriname. Finally, we have the yearly graduation rate, that is, the number of graduated students from the university as a share of the school age population at the tertiary level (variable name: afgest_pop).

The wage differential is the ratio of the GDP per capita in PPP US dollars of Suriname to the GDP per capita in PPP US dollars of the Netherlands. We used data from the World Bank to calculate this ratio. Appendix A provides an overview of the used variable names and their sources for the above mentioned proxies. Figures 1 to 6 in Appendix B give a graphical impression of the data. Appendix $\mathrm{C}$ gives some summary statistics of the growth rates of these variables. Appendix D explains a few of the abbreviations.

\section{Methodology}

As can be seen from the graphs, the data are trending, either upwards or downwards. We also would like to allow for the possibility of long-run relationships, as it is most likely that such variables as emigration and education have a long-run relationship with each other and also that shocks may last for a long time, perhaps even permanently. To allow for the estimation of long-run effects, we therefore rely on an error correction model.

We have two models, one in which the emigration rate is linked with the wage differential, and one in which education levels are linked with emigration rates. We denote the 
left-hand side variable as $y_{t}$, which is the log-transformed emigration rate in the first model and which is the log-transformed education level (one of the four) in the second model. The explanatory variable on the right-hand side is denoted as $x_{t}$, which is the log-transformed wage differential in the first equation and the log-transformed migration rate in the second model.

The econometric time series model for both cases is given by

$$
y_{t}=\mu+\lambda y_{t-k}+\beta_{1} x_{t}+\beta_{2} x_{t-k}+\varepsilon_{t}
$$

where $k$ can be 1, 2, 3 or 4 to allow for various time effects. The equation in (1) can be written in the so-called error correction format, which is given by

$$
y_{t}-y_{t-k}=\mu+\beta_{1}\left(x_{t}-x_{t-k}\right)+(\lambda-1)\left(y_{t-k}-\frac{\beta_{1}+\beta_{2}}{1-\lambda} x_{t-k}\right)+\varepsilon_{t}
$$

The short-run effect of the explanatory variable is $\beta_{1}$ and the long-run effect is

$$
\frac{\beta_{1}+\beta_{2}}{1-\lambda}
$$

We use the Nonlinear Least Squares Routine in EViews to directly estimate these long-run and short-run effects and their associated standard errors. Diagnostic tests for residual autocorrelation show that the model in (2) adequately fits the data.

\section{The results}

We start with the supposed link between wage differentials and the emigration rate. From Table 1 in Appendix $\mathrm{E}$ we see that there is no significant short-run effect of a wage differential on the emigration rate but that does exist a positive long-run effect (see the cases where $k$ in (1) is equal to 3 and 4). So, we obtain moderate support for the first hypothesis.

When we link the education levels with the emigration rate, we see from Table 2 in the same Appendix E that there is a strong negative effect of emigration on the number of 
graduated students from university. This effect is there for the short-run within the range of 0.14 to -0.32 (average -0.25 ), and for the long-run in the range of -1.52 to -1.80 (average 1.68). Hence, the long-run effect is about 7 times as large as the short-run effect. We also obtain evidence for negative long-run effects for education at the tertiary and secondary level, approximately of size -0.2. For these two education types, no short-run effects are statistically significant. Finally, as primary education is obligatory in Suriname, we would expect no effects of emigration on enrolment at that level. When we look at the final panel of Table 2, we indeed find results that match our expectations as no significant effects are found.

In sum, our main conclusion is that there are strong signs of brain drain effects for Suriname, and not of brain gain. Brain drain seems to most effect the education at the university level.

\section{Conclusion}

The purpose of this paper was to test the brain gain hypothesis for Suriname using time-series data for the period 1972 - 2009. The prospect of emigrating and acquiring higher wages abroad when being high skilled might stimulate people to achieve higher education levels in the home country. Using an error correction model we arrived at the conclusion that higher wage differentials between the home and destination country increases emigration from Suriname to the Netherlands in the long run. Additionally, contrary to the hypothesis that emigration prospects increase the level of education we find negative long-run effects of emigration on human capital formation at secondary and tertiary schooling levels. The effect of emigration on the rate of graduation from the university is negative in both the short and long term. Unsurprisingly, no effect was found at primary schooling level, as education at the primary level (for the age of 7 to 12) is compulsory.

The key finding of our study is that Suriname concerns a case of brain drain, and not of brain gain. The stock of the higher educated Surinamese decreases as emigration increases, and of course, when emigration decreases, education levels in Suriname increase.

From our paper it is evident that emigration is fuelled by higher wages paid abroad. Policy makers in Suriname should attract highly skilled people to stay in Suriname or to return to Suriname by offering them job opportunities from where they can build on their own career and earn higher wages. Two main problems might obstruct the implementation of this policy and therefore they need attention. 
Firstly, as also noted in Rosenzweig (2005), poor institutions in the home country might induce highly skilled individuals to emigrate. In general elderly highly positioned people are reluctant to grant the opportunity to younger and high educated people to build on their career into top positions and this may also hold in Suriname. Ethnic fractionalization could also induce the highly skilled to emigrate (Docquier et al. 2007). Due to its ethnic and political fractionalization, Suriname is prone to patronage politics. Jobseekers might be mainly judged by their political background (and ethnic background since political parties are mainly based on ethnic idealism) and not as much on their diplomas and capabilities. Easterly and Levine (1997) and Alesina et al. (2003) already showed that ethnic fractionalization has a negative impact on the economic growth in Africa.

Secondly, technological constraints in the home country (Fan \& Stark 2007b and Calí 2008) could discourage young highly skilled individuals to stay in the home country or to return from the destination country. An environment in which the educated cannot utilize their acquired skills might push them away to a foreign country. Technological change could therefore be a catalyst for brain gain. .

We do not recommend restrictive migration policies since these might reduce innovation, increase illegal migration and fuel brain waste, where highly educated individuals cannot find suitable employment opportunities in the home country and thus remain unemployed or overeducated. International collaboration between Suriname and especially the Netherlands on developing tertiary education opportunities, improving institutions through technical training and transferring technology can help reducing the brain drain effects. At the political level, countries should support policies that encourage return migration.

Further research on the above mentioned policy recommendations and identified problems are necessary. Interviewing subjects on the characteristics of emigration and their experiences on the abovementioned issues could provide information to build micro data sets for further research. 


\section{Appendix A Variables and sources}

\section{Acronym}

Schlenrlpr

Schlenrlsc

Schlenrltr

Afgest_pop

Number of graduated students as a share of

the school age population at tertiary level

Mig_emig

Wage_diff

\section{Variables}

School enrolment rate at primary level

School enrolment rate at secondary level

School enrolment rate at the university

Number of emigrants from Suriname to (as a share of the school age at primary level)

(as a share of the school age at secondary level)

(as a share of the school age at tertiary level)

AdeKUS (2011)

and GBS

AdeKUS (2011)

GBS (2011)

the Netherlands as a share of population of Suriname

Real GDP per capita of Suriname in PPP dollars

(2011) to real GDP per capita of the Netherlands in PPP dollars 


\section{Appendix B Figures}

\section{SCHLENRLPR}

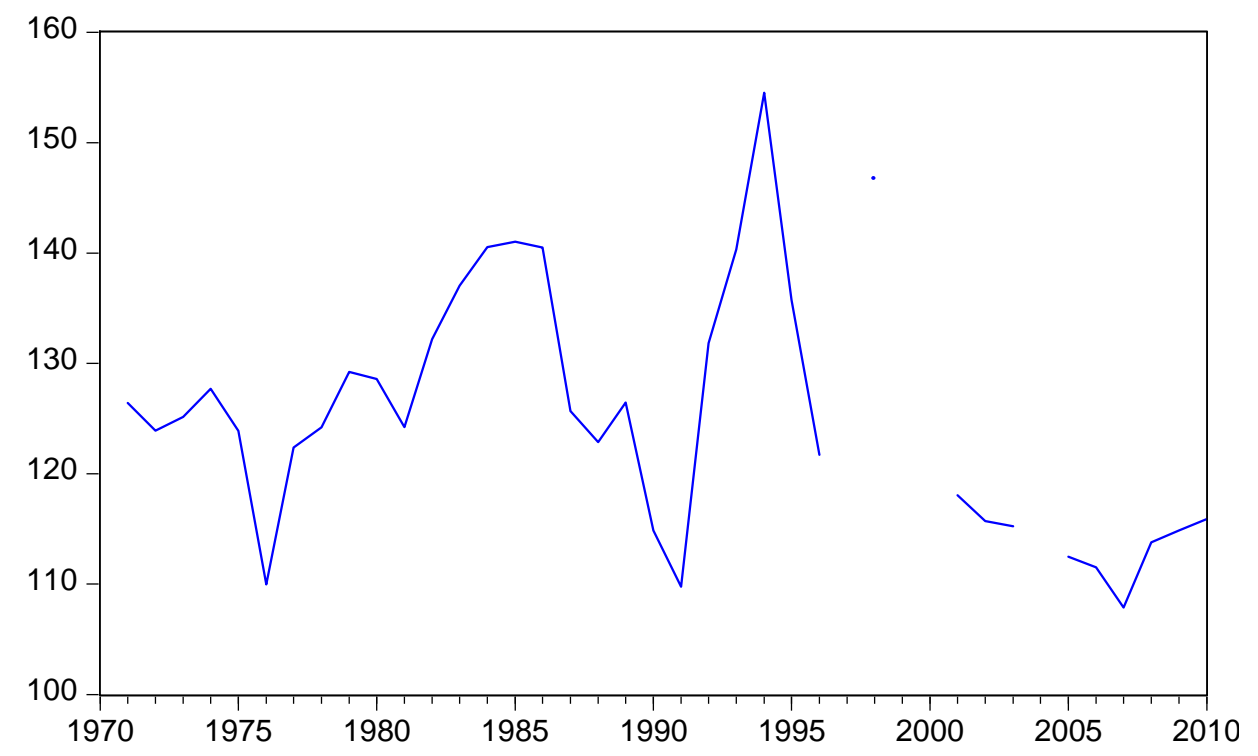

Figure 1: School enrolment rate at primary level (as a share of the school age at primary level) (1971-2010) 
SCHLENRLSC

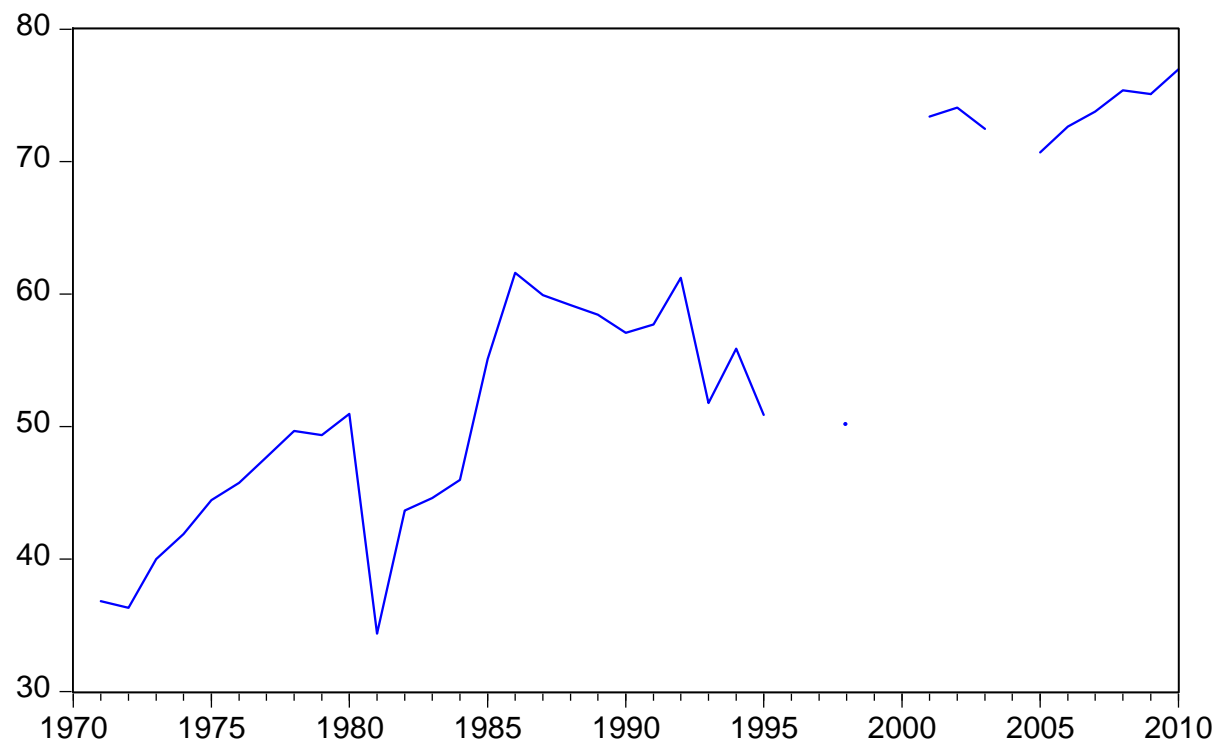

Figure 2: School enrolment rate at secondary level (as a share of the school age at secondary level) (1971-2010) 
SCHLENRLTR

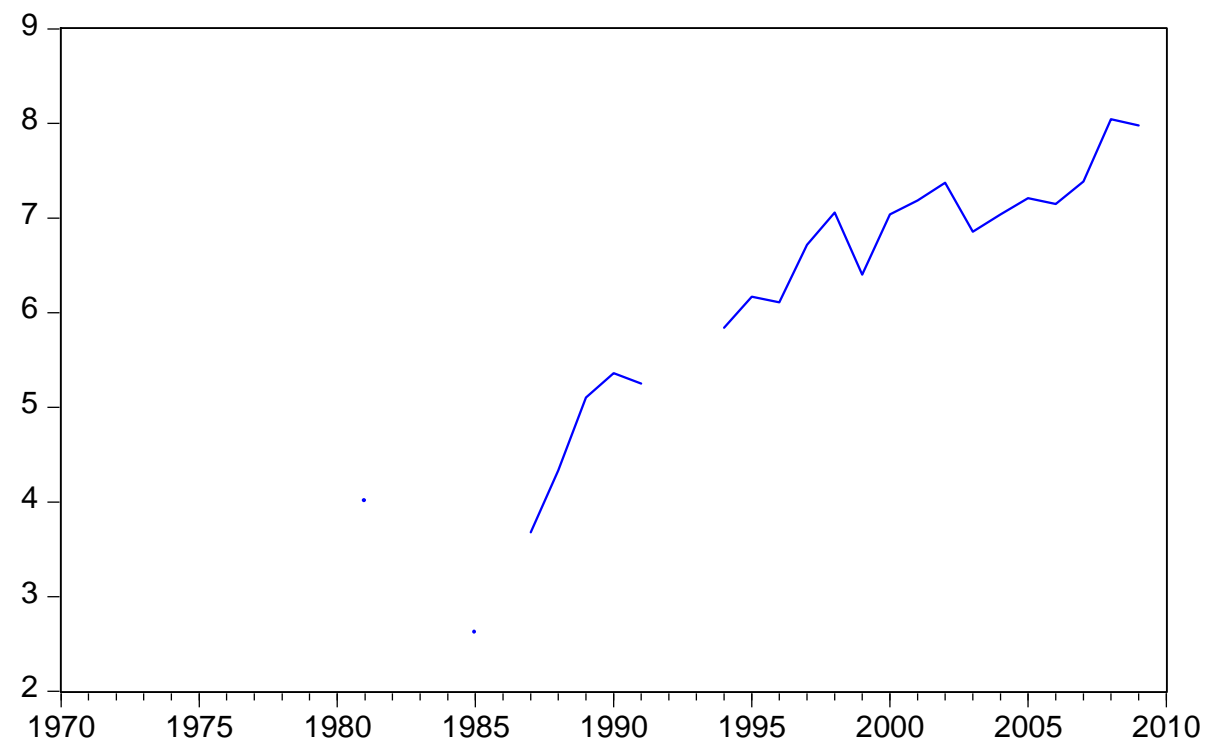

Figure 3: School enrolment rate at the university (as a share of the school age at tertiary level) (1981 - 2009, with missings) 


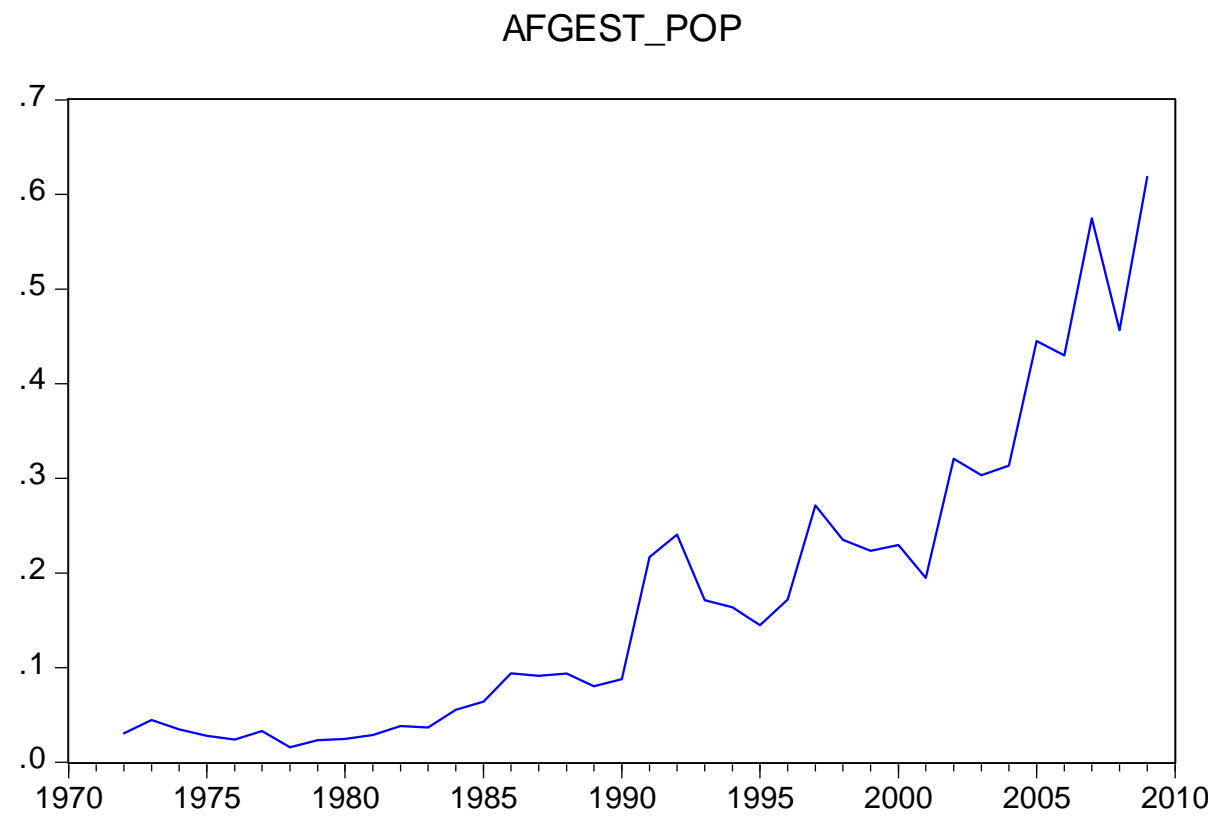

Figure 4: Number of graduated students as a share of the school age population at tertiary level $(1972-2009)$ 
MIG_EMIG

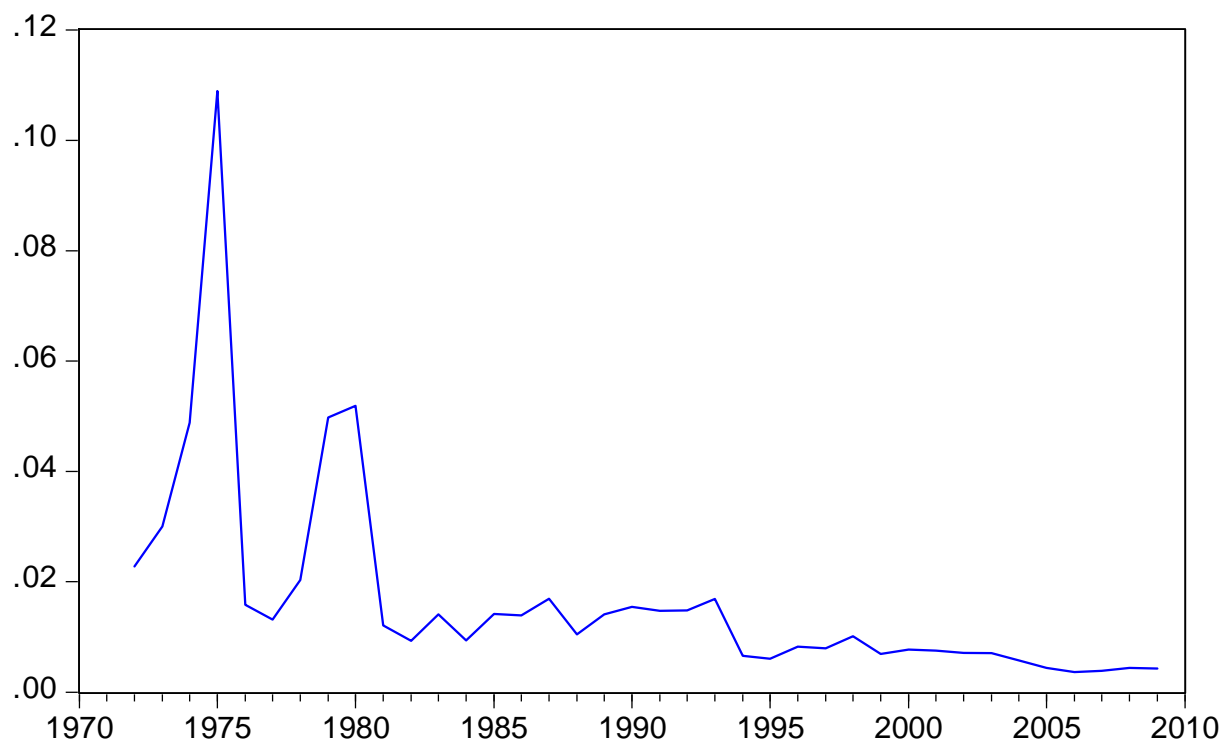

Figure 5: Number of emigrants from Suriname to the Netherlands as a share of population of Suriname (1972 - 2009) 
WAGE_DIFF

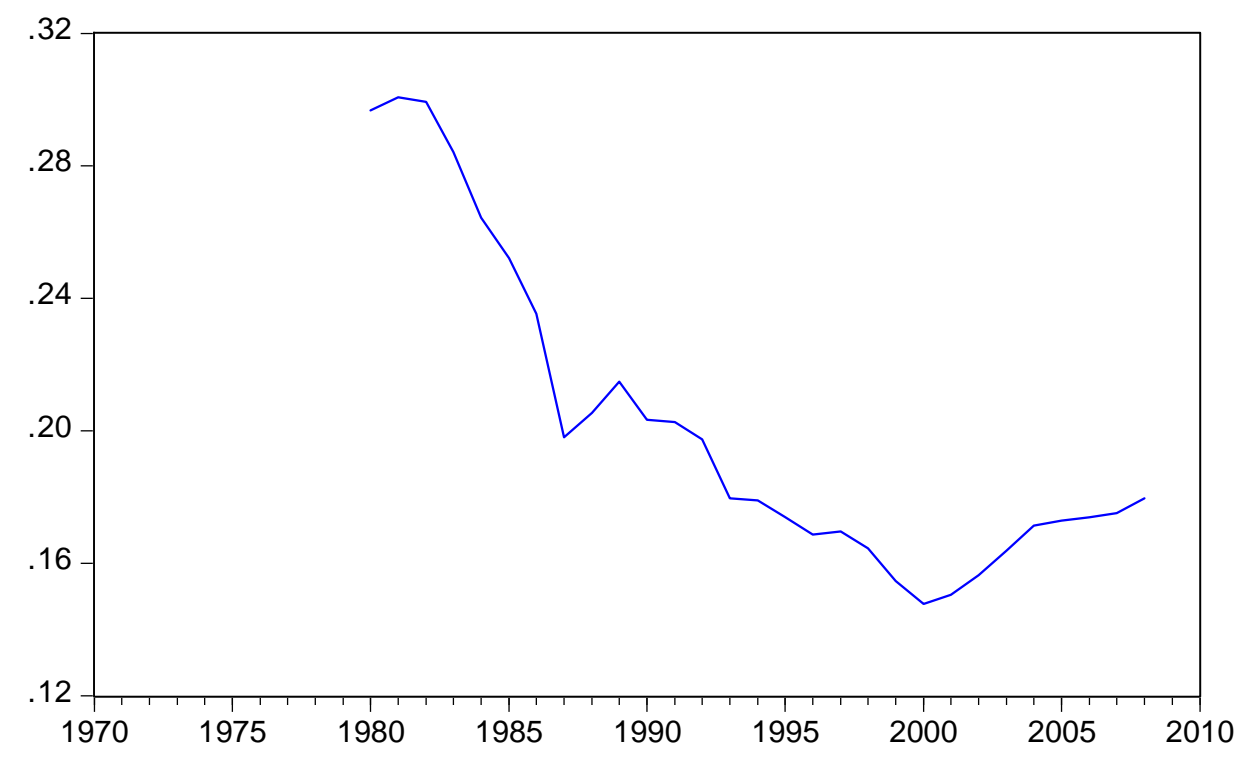

Figure 6: Real GDP per capita of Suriname in PPP dollars to real GDP per capita of the Netherlands in PPP dollars (1980 - 2008) 
Appendix C Descriptive statistics of various growth rates

$\begin{array}{lcllll}\text { Variable } & \text { Mean } & \text { Median } & \text { Minimum } & \text { Maximum } & \text { St deviation } \\ \text { Mig_emigr } & -0.045 & -0.008 & -1.928 & 0.897 & 0.529 \\ \text { Schlenrlpr } & -0.001 & -0.0001 & -0.129 & 0.183 & 0.067 \\ \text { Schlenrlsc } & 0.013 & 0.021 & -0.394 & 0.240 & 0.104 \\ \text { Schlenrltr } & 0.035 & 0.026 & -0.098 & 0.164 & 0.068 \\ \text { Afgest_pop } & 0.081 & 0.032 & -0.749 & 0.904 & 0.298 \\ \text { Wage_diff } & -0.018 & -0.004 & -0.173 & 0.046 & 0.050\end{array}$




\title{
Appendix D Abbreviations
}

\author{
AdeKUS Anton de Kom University of Suriname \\ CBB Central Bureau for Civil Affairs of Suriname \\ CBS Central Bureau of Statistics Netherlands \\ GBS General Bureau of Statistics of Suriname \\ IMF International Monetary Fund \\ UIS UNESCO Institute for Statistics
}

UN DESA United Nations Department of Economic and Social Affairs 


\section{Appendix E}

\section{Estimation results}

Table 1: Estimation results for the correlation between the emigration rate and the wage differential (Newey West HAC estimated standard error in parentheses). Boldface estimates are significant at the $5 \%$ level.

$\begin{array}{llll}k \text { in (2) } & \text { Short-run effect } & \text { Long-run effect } & \mathrm{R}^{2} \\ 1 & & & \\ 2 & -1.432(1.046) & 0.230(0.720) & 0.687 \\ 3 & -0.200(1.028) & 0.717(0.557) & 0.667 \\ 4 & 0.790(1.087) & \mathbf{1 . 3 2 0}(0.216) & 0.684 \\ & 0.984(1.185) & \mathbf{1 . 3 9 0}(0.323) & 0.768\end{array}$


Table 2: Estimation results for the correlation between the education enrolment and the emigration rate (Newey West HAC estimated standard error in parentheses). Boldface parameters are significant at the $5 \%$ level.

\begin{tabular}{|c|c|c|c|c|}
\hline Variable & $k$ in (1) & Short-run effect & Long-run effect & $\mathrm{R}^{2}$ \\
\hline Graduated & 1 & $\mathbf{- 0 . 1 4 1}(0.037)$ & $-1.522(0.280)$ & 0.108 \\
\hline University & 2 & $\mathbf{- 0 . 2 3 6}(0.043)$ & $\mathbf{- 1 . 6 4 0}(0.274)$ & 0.186 \\
\hline \multirow[t]{2}{*}{ Students } & 3 & $\mathbf{- 0 . 3 2 4}(0.117)$ & -1.743 (0.185) & 0.432 \\
\hline & 4 & $\mathbf{- 0 . 2 8 4}(0.169)$ & $\mathbf{- 1 . 7 9 5}(0.370)$ & 0.276 \\
\hline Enrolment & 1 & $0.033(0.053)$ & $\mathbf{- 0 . 2 5 7}(0.052)$ & 0.629 \\
\hline Tertiary & 2 & $0.007 \quad(0.053)$ & $\mathbf{- 0 . 2 1 4}(0.075)$ & 0.789 \\
\hline \multirow[t]{2}{*}{ Level } & 3 & $0.005 \quad(0.024)$ & $\mathbf{- 0 . 2 0 4}(0.054)$ & 0.928 \\
\hline & 4 & $-0.208(0.219)$ & $\mathbf{- 0 . 4 2 9}(0.230)$ & 0.306 \\
\hline Enrolment & 1 & $0.024 \quad(0.042)$ & $-0.213(0.054)$ & 0.339 \\
\hline Secondary & 2 & $0.002 \quad(0.027)$ & $\mathbf{- 0 . 2 3 0}(0.056)$ & 0.523 \\
\hline \multirow[t]{2}{*}{ Level } & 3 & $-0.027(0.026)$ & $\mathbf{- 0 . 2 0 3}(0.052)$ & 0.443 \\
\hline & 4 & $-0.015(0.039)$ & $\mathbf{- 0 . 1 7 2}(0.069)$ & 0.448 \\
\hline Enrolment & 1 & $0.020 \quad(0.020)$ & 0.020 & 0.177 \\
\hline Primary & 2 & $0.016 \quad(0.017)$ & $0.026 \quad(0.039)$ & 0.320 \\
\hline \multirow[t]{2}{*}{ Level } & 3 & $0.014 \quad(0.022)$ & $0.026(0.036)$ & 0.399 \\
\hline & 4 & $0.023(0.031)$ & 0.046 (0.039) & 0.424 \\
\hline
\end{tabular}




\section{References}

Alesina, A., Devleeschauwer, A., Easterly, W., Kurlat, S. \& Wacziarg, R. (2003), Fractionalization, Journal of Economic Growth, 8 (2), 155-94.

Batista, C., Lacuesta, A. \& Vicente, P. (2009), Testing the 'Brain Gain Hypothesis: Micro Evidence from Cape Verde, IIIS Discussion Paper no. 282, The University of Dublin.

Beine, M., Docquier, F. \& Rapoport, H. (2001), Brain Drain and Economic Growth: Theory and Evidence, Journal of Development Economics, 64, 275-289.

Beine, M., Defoort, C. \& Docquier, F. (2007), A Panel Data Analysis of The Brain Gain, Discussion Paper no. 24, Université Catholique de Louvain.

Boucher, S., Stark, O., \& Taylor, E. (2005), A Gain with a Drain? Evidence from Rural Mexico on the New Economics of the Brain Drain, Agriculture and Resource Economics Working Paper, UCS University of California Davis.

Calí, M. (2008), Migration Restrictions and the 'Brain Drain’: The Wrong Response to an Illdefined Problem, Opinion, no. 98, Overseas Development Institute.

Docquier, F. (2006), Brain Drain and Inequality Across Nations, IZA Discussion Paper no. 2440, Institute for the Study of Labor, Bonn.

Docquier, F., Lohest, O. \& Marfouk, A. (2007), Brain Drain in Developing Countries, The World Bank Economic Review, 21(2), 177-191.

Eggert, W., Krieger, T. \& Meier, V. (2009), Education, Unemployment and Migration, IFO Working Paper no. 78., University of Muenchen.

Easterly, W. \& Levine, R. (1997), Africa's Growth Tragedy: Policies and Ethnic Divisions, Quarterly Journal of Economics, 112 (4), 1203 - 1250. 
Fan, S. \& Stark, O. (2007a), International Migration and 'Educated Unemployment', Journal of Development Economics, 83, 76-87.

Fan, S. \& Stark, O. (2007b), The Brain Drain, 'Educated Unemployment', Human Capital Formation, and Economic Betterment, Economics of Transition, 15 (4) , 629-660.

International Monetary Fund (IMF) (2011), Suriname: 2011 Article IV Consultation, IMF Country Report, no. 11/256.

International Organization for Migration (2010), World Migration Report. Geneva.

Nurse, K. (2006), The World Today: Migration and Development in the Caribbean, University of the West Indies, St. Augustine Campus.

United Nations Department of Economic and Social Affairs (UN DESA) (2009), Global Migration Database, Retrieved January 16, 2011, from http://esa.un.org/migration/

Rosenzweig, M. (2005), Consequences of Migration for Developing Countries, United Nations Expert Group Meeting on International Migration and Development, United Nations Secretariat, New York.

Stark, O., Helmenstein, C., \& Prskawetz, A. (1998), Human Capital Depletion, Human Capital Formation, and Migration: A Blessing or a 'Curse'? Economics Letters, 60, 363-367.

Soedhwa, B. (2005), Longitudinal Analysis of Possible Links between Poverty and Mortality in Suriname, General Bureau of Statistics of Suriname, Paramaribo.

World Bank (2011), World Bank Development Indicators. Retrieved September 15, 2011, from http://databank.worldbank.org 